\title{
Effect of Collaborative Teaching on Secondary School Students' Achievement in and Attitude towards Mathematics
}

\author{
Sabainah Oyebola Akinoso ${ }^{1}$, Festus Oladimeji Olafare ${ }^{2}$, Zainab Bolaji Oye-Akinoso ${ }^{3}$ \\ ${ }^{1}, 2$ Faculty of Education, Department of Science and Technology Education, University of Lagos, Nigeria \\ ${ }^{3}$ Department of Geoscience, Faculty of Art and Science, Georgia State University, Atlanta
}

\begin{abstract}
The effect of collaborative strategy on secondary school student's academic achievement and attitude towards mathematics in Lagos state was investigated in this study. It was an experimental study, and the design was pre-test, control group quasi-experimental. All secondary schools in educational district II picked randomly from six educational districts in Lagos state constitute the population for the study. The selection of two local government areas was done with simple random, one school was selected from each local government using random sampling, and one intact class of junior secondary school II selected from the two schools represents the study sample. The sample size was 60 junior secondary school II students. The instruments used for collecting data are Mathematics Achievement Test (MAT) and Students Mathematics Attitude Questionnaire (SMAQ). The instruments were validated, trialtested. The reliability coefficients of the two instruments were 0.88 and 0.89 respectively. Analysis of Covariance was used to analyse the collected data and to measure the two stated null hypotheses. From the results of the study, the effect of the treatment is not significant on student achievement in mathematics but, a significant difference exists in students' attitude to mathematics with the use of collaborative strategy. Mathematics teachers should ensure proper enhancement of collaborative strategy with thorough monitoring of the students in different groups while teaching mathematics.
\end{abstract}

Keywords: Collaborative strategy; performance; academic achievement; attitude; mathematics.

\section{INTRODUCTION}

$\mathrm{M}$ athematics is a core subject linked generally to the development of any nation. It is a science of order. Everything about mathematics is well arranged and logical. It entails bringing together some piece to form a whole in terms of material or idea. Human endeavors have been influenced by mathematics through creativity, community practices, and cultural background. Mathematics is essential in public decisions and the nation's economy. The basic knowledge of mathematics starts from school while the application of the knowledge is required throughout the human lifetime. Mathematics is relevant to a wide variety of academic subjects due to its universal nature. If a student is very good at mathematics, such knowledge will assist the students in other fields of study. Mathematics sharpens the brain, this might be the reason why Akinoso, (2017) quipped that if a student is good in mathematics, every other subject will be easy to handle. Thomson (2018) also averred that a student who does not perform well in mathematics will end up struggling in other fields of study and such students' career options will be limited. In sciences, chemical formulae cannot be ruled out, understanding of such formula requires mathematical knowledge. The measurement, weighing, drafting, data analysis with appropriate statistical tools in both sciences and other subjects required adequate knowledge in mathematics.

Mathematics serves as the bases for technology this implies that technology cannot stand in isolation without mathematics. Mathematics forms the foundation upon which technology knowledge is built and everything in technology is calculation originated from mathematics. Without mathematics, there is no technology, and without science and technology, society cannot stand. The skills in mathematics are used by every human daily whether realizing it or not. Due to the importance of mathematics, ways of improving the students' performance and attitude become an important issue. When students have adequate knowledge and skills in mathematics it will help such students in technical skills required in every sector before securing a job.

In general, the performance of the student in mathematics over time has been recorded as poor leading to a mass failure (Vanguard, 2015). Despite the importance of mathematics and as an important subject in the curriculum of basic education level and secondary school, students still perform poorly in the subject. Students viewed mathematics in abstract form and as a subject that cannot be understood easily. Mathematics has unique nature that differentiates it from other subjects. The abstract and symbolic nature of mathematics makes it unique among every other subject. This nature is affecting mathematics learning since learners viewed it as a difficult subject that is meant for only talented learners. Busari and Akinoso, (2020) submitted that highly mathematics-anxious learners have characteristics of a strong tendency to avoid mathematics, undercuts their mathematics competence, and forecloses high-and-mighty career paths. Most students dread mathematics, and anxiety possessed leads to the kind of attitude possessed towards the subject.

The abstract is one of the nature and characteristics of mathematics served as the clue for discovering how to handle 
the teaching to reduce to minimal level this abstract nature. Though, mathematics is dread by the majority of the students but, if the teacher adopts various methods that can meet the needs of every student, especially the activity-based strategy and students' centered, it will help students in learning mathematics without stress. It will also change the students' attitudes and feelings towards mathematics. Teaching with relevant materials, use of different strategies that are studentcentered such as concrete-representational-abstract strategy, incorporation of information and communication technology in teaching, collaborative strategy and others might serve as a remedy to learning difficulties in mathematics. In learning, the environment should be made conducive, allow free access to learning, and contributions from students. A collaborative learning strategy is a form of strategy that gives every student equal access and opportunity to learning.

Collaborative learning occurred when groups of students work together in searching for meaning, understanding, and solutions to create an artifact of learning (Akinoso, 2017). Students can learn mathematics by working together with some other students. A collaborative teaching strategy is a teaching and learning strategy that involves small group learning ranging from two to five students in a group to exchange ideas to promote learning a certain concept. The group might be heterogeneous or homogeneous according to the gender of students or students' academic ability. The collaborative strategy involves a thorough explanation of the concept by the instructor before grouping. In different groups, ideas are exchanged among every member of the group and the teacher, students thinking is improved, students attained problem-solving skill, and students' understanding is improved. Series of points of view were presented by the participants in response to others' ideas. In collaborative learning, the objectives are presented, various activities are involved that improve understanding of the given concept.

The researchers such as Johnson, Johnson, and Smith, (2007) concluded that collaborative learning can promote academic and social educational outcomes. Collaborative skills are essential in this present age to meet challenges in learning. The collaboration skills include listening skills, expressing ideas and opinions, following directions, asking for help, giving and receiving compliments and constructive criticism, and negotiating. Firestone, (2006) emphasized that collaboration largely depends on the ability to join in, working with others, listening to what others will say, and encouraging others to speak up and speaking up yourself when having an idea. Apart from building collaborative skills, work in collaboration with other students will lead to deep learning and the problem-solving ability of the students is increased. Learning with peers in mathematics class will allow students to gain various ideas from colleagues, open the students' eyes to different approaches in solving mathematical problems, and improve the students' boldness and thinking ability.

Thayer-Bacon, (2000) emphasized that if students relate together in groups it will assist in gaining critical thinking skills. Olanrewaju, (2019) in a study on collaborative learning technique on achievement found that collaborative learning technique improve students' achievement in mathematics. Johnson, (2006) found collaborative learning effective in improving academic achievement. Galton, Hargreaves, and Pell (2009) found that the group taught with collaborative strategy had better achievement than the other group. Also, Stoner, (2004) concluded the positive effect of cooperative strategy on mathematics achievement of students.

Attitude is another construct considered in this study which is an emotional disposition to learning. Attitude can be positive or negative depends on students' emotions. A positive attitude can be of great benefit to learning while a negative attitude can lead to discouragement due to poor results. Attitude influences mathematics achievement, literacy, and reasoning. Kennedy (2019) averred that attitude reflects the value, selfconfidence, enjoyment, motivation, and anxiety of students towards mathematics. Attitude towards mathematics implies students' predisposition towards mathematics (Fonseca, 2012) which can either be positive or negative. Kennedy (2019) asserted that early engagement in Mathematics prevents negative attitudes. A positive attitude motivates students to perform well and proceed in mathematics learning and mathematics relate courses while a negative attitude might result in failure and discouragement. Attitude Khaoo and Ainley, (2005) is formed as a result of teaching practices, response to curriculum, and organizational arrangement. Attitude is an important construct when it comes to the issue of learning. If a negative attitude is built upon a certain subject it requires a lot of effort and practices before it can be changed or reduced to a minimal level. Attitude is ambiguous and cannot be given a specific definition but needs to be developed further. Attitude to mathematics is the possibility to engage in or stay away from activities involving mathematics that is the like or dislike of mathematics. Attitude as affects mathematics learning was considered in this study. Bii, (2019) found a significant effect of collaborative strategy on students' attitude to mathematics. Ifamuyiwa and Akinsola, (2008) found a positive effect of cooperative learning strategy on students' mathematics attitude to learning.

\section{Statement of the Problem}

Mathematics contributes to the existence of virtually everything in life, application of which is found everywhere. The students dread mathematics and always find a way to dodge mathematics and related subject. The negative attitude possessed towards this subject always affects the students' performance. Students' performance in mathematics is not encouraging. A lot of researchers was carried out in different aspect to improve the students' performance in mathematics but the issue of poor performance is still in existence. Several improvement measures and logics have been introduced to minimize the problem of mass failure in mathematics, different strategies were studied, but if students can understand the logic behind the improvement measures such as teaching and learning strategy it will help them in almost 
everything in their future career, it will also help in the improvement of science and technology which will contribute to the development of the nation. This study, therefore, checked the effect of collaborative strategy on achievement and attitude of students to mathematics learning.

\section{Objective}

The objectives of this study are listed below:

1. To examine the effect of collaborative strategy on junior secondary school student's academic performance in mathematics in Lagos State.

2. To examine the effect of collaborative strategy on junior secondary school students' attitude to mathematics in Lagos State, Nigeria.

\section{Hypotheses}

$\mathbf{H O}_{1}$ : Collaborative strategy has no significant difference on student achievement in mathematics

$\mathbf{H O}_{2}$ Collaborative strategy has no significant difference on student attitude towards mathematics

\section{METHODOLOGY}

All secondary schools students in educational district II picked randomly from six educational districts in Lagos State form this study population. Two local government areas were selected with a simple random technique, one school was selected from each local government using random sampling technique, and one intact class of junior secondary school II selected from the two schools represents the study sample. The two selected schools were assigned for treatment randomly. The students in the experimental group were exposed to collaborative strategy and those in control with the traditional or normal way of teaching without grouping and group activities. In the experimental group, the students were group into a group of five students in a group. The groups were obtained and consist of students with heterogeneous abilities. This was obtained by using the ability test exercise to test the students' ability levels before grouping. The sample size was 60 junior secondary school II students.

The instruments used were Mathematics Achievement Test (MAT) and Students Mathematics Attitude Questionnaire (SMAQ). The questions used for the mathematics achievement test were selected from Basic Education Certificate Examination (BECE) past questions been standardized questions. The topics used for this instrument were selected based on chief examiners' reports that show the area where students perform poorly. The topics used were Fractions (Word problems infractions) and Algebraic expression. The mathematics achievement question is a 25item multiple-choice. The attitude scale was adapted from Tapia and Marsh's (2004) attitude towards mathematics inventory of 40 -items that covers self-confidence, value, enjoyment, and motivation.
The reliability coefficients of Tapia and Marsh (2004) inventory were established for college and students in High school (Tapia \& Marsh, 2004) respectively and the confirmatory factor analysis confirmed the structure of the four-factor. The alpha values were determined using Cronbach's alpha that yielded these results: self-confidence (0.95), value (0.89), enjoyment (0.89), and motivation (0.88). The instrument for this study was a Likert type of strongly agree, agree, disagree, and strongly disagree with 4, 3, 2, 1, respectively for positively worded questions in the questionnaire, and the scores were reversed for the questions that appear in negative form. The instruments were validated, and trial-tested using twenty-five junior secondary school II students select from a school from other local government areas that were not part of the study to confirm the validity of the selected instruments. The reliability coefficients of the two instruments were determined as 0.88 and 0.89 using KR- 20 and Cronbach alpha respectively. Two null hypotheses were generated and measured at a 0.05 level of significance.

A pre-test was given to both groups before instruction. After the pre-test, each class was taught for a period of 2-weeks on the topic of word problems on fractions and algebra. The two groups were properly monitored. After the classes, a post-test on mathematics achievement and mathematics attitude scale was administered to the two groups. The study lasted for five weeks, one week for pre-test, one week for administering instruments to put the experimental group to different ability levels, two weeks for the treatment, and one week for posttest. The statistic measure used was (ANCOVA) to analyze the collected data and to measure the two stated null hypotheses.

\section{RESULT}

HO$_{1}$ : Collaborative strategy has no significant difference on student achievement in mathematics

Table 1: Analysis of Covariance of Collaborative Strategy and Achievement in Mathematics

\begin{tabular}{|c|c|c|c|c|c|}
\hline Source & $\begin{array}{c}\text { Type III } \\
\text { Sum of } \\
\text { Sq. }\end{array}$ & df & $\begin{array}{c}\text { Mean } \\
\text { Sq. }\end{array}$ & F & Sig. \\
\hline $\begin{array}{c}\text { Corr. } \\
\text { Model }\end{array}$ & $301.863^{\text {a }}$ & 2 & 150.932 & $\begin{array}{c}22.3 \\
85\end{array}$ & .000 \\
\hline Intercept & 240.723 & 1 & 240.725 & $\begin{array}{c}35.7 \\
03\end{array}$ & .000 \\
\hline Pre achieve & 293.042 & 1 & 293.047 & $\begin{array}{c}43.4 \\
63\end{array}$ & .000 \\
\hline Grp. & 23.445 & 1 & 23.444 & $\begin{array}{c}3.47 \\
7\end{array}$ & .067 \\
\hline Error & 384.321 & 57 & 6.742 & & \\
\hline Total & 8325.001 & 60 & & & \\
\hline $\begin{array}{c}\text { Corrected } \\
\text { Total }\end{array}$ & 686.184 & 59 & & & \\
\hline \multicolumn{7}{|c|}{ a. R Sq. $=.440$ (Adj. R Sq. $=.420)$} \\
\hline
\end{tabular}

Table 1 shows that treatment has no significant effect $(0.067)$, $\mathrm{F}_{1,60}=3.477, \mathrm{p}>0.05$ on achievement in mathematics. Since no significant effect of the treatment on achievement in mathematics, $\mathrm{HO}_{1}$ is hereby not rejected. Therefore, there is 
no significant effect of collaborative teaching strategy on secondary school students' achievement in mathematics.

$\mathbf{H O}_{2}$ Collaborative strategy has no significant difference in student attitude towards mathematics.

Table 2: Analysis of Covariance of Students' Attitude to Mathematics

\begin{tabular}{|c|c|c|c|c|c|}
\hline Source & $\begin{array}{c}\text { Type III } \\
\text { Sum of } \\
\text { Sq. }\end{array}$ & df & $\begin{array}{c}\text { Mean } \\
\text { Sq. }\end{array}$ & F & Sig. \\
\hline $\begin{array}{c}\text { Corrected } \\
\text { Model }\end{array}$ & $578.553^{\mathrm{a}}$ & 2 & 289.276 & $\begin{array}{c}25.9 \\
92\end{array}$ & .000 \\
\hline Intercept & 435.325 & 1 & 435.323 & $\begin{array}{c}39.1 \\
14\end{array}$ & .000 \\
\hline $\begin{array}{c}\text { Pre } \\
\text { attitude }\end{array}$ & 38.553 & 1 & 38.551 & $\begin{array}{c}3.46 \\
4\end{array}$ & .068 \\
\hline Grp. & 367.912 & 1 & 367.910 & $\begin{array}{c}33.0 \\
57\end{array}$ & $\begin{array}{c}.000 \\
*\end{array}$ \\
\hline Error & 634.383 & 57 & 11.130 & & \\
\hline Total & $\begin{array}{c}40126.0 \\
1\end{array}$ & 60 & & & \\
\hline $\begin{array}{c}\text { Corrected } \\
\text { Total }\end{array}$ & $\begin{array}{c}1212.93 \\
5\end{array}$ & 59 & & \\
\hline \multicolumn{7}{|c|}{ R Sq. $=.477$ (Adj. R Sq. $=.459)$} \\
\hline
\end{tabular}

Table 2 shows a significant effect of treatment $F_{1,60}=33.057$, p $>0.05$ on student attitude to mathematics. The significant level is given as .000 . Hence hypothesis two is hereby rejected. The result shows that a significant different exist between the collaborative teaching strategy and student attitude to mathematics. Collaborative strategy influences the attitude of student to mathematics.

\section{DISCUSSION}

This study established that collaborative strategy has no significant effect on student achievement in mathematics. This implies that collaborative strategy does not affect the academic achievement of junior secondary school mathematics. The finding is in consonance with the findings of ..... who revealed that collaborative teaching strategy did not improve the students' academic achievement in mathematics. The report of this study contradicts Olanrewaju, (2019) findings who found the effective of collaborative learning technique in mathematics. Johnson, (2006) found collaborative learning effective in improving academic achievement which also contradicts the report of this study. The finding of Galton, Hargreaves, and Pell (2009) on the group taught with collaborative strategy performed better than the other group contradict this study's finding. The results of this study also negate the findings of Akdeniz, (2008).

There was a significant difference in students' attitudes to mathematics with the use of collaborative strategy. The change in attitude might be as a result of the interaction among the students in different groups which made the students felt it as the normal interaction witness outside the class. Collaborative learning strategy built interpersonal relationship among the students thus improve their attitude to mathematics learning, Collaborative learning actively involves every student in the process of learning, allows social interaction among the group, and entails student confidence in mathematics learning. The interpersonal relationship that exists in collaborative learning which allow the student contributions in language they understand, and deliberation until mastery is attained help improve the student attitude towards learning mathematics. The findings align with the result of Bii, (2019) that collaborative strategy improves students' attitude to mathematics. This study is also consistent with the findings of Ifamuyiwa and Akinsola, (2008) on students' attitudes towards mathematics.

\section{CONCLUSION}

It was established from this study that collaborative learning strategy did not improve the academic achievement of junior secondary school mathematics but the strategy has a positive effect on the attitude of junior secondary school students by changing their attitude to mathematics learning. This is because the student might find fun in discussing mathematics among themselves as if in an ordinary argument in which everybody has the chance of presenting ideas, think over the ideas presented before the conclusion. The interpersonal relationship during discussion contributes to the change in attitude of students to mathematics learning. Change in attitude positively with time will eventually contribute to and improve the performance of students in mathematics. The study recommended that the secondary school mathematics teachers should use a collaborative strategy in teaching to change the negative attitude of the student to positive which with time improve the academic achievement in mathematics.

\section{REFERENCES}

[1] Akinoso, S. O. (2017). Information communication technology and collaborative skills on students with learning difficulties in mathematics, 1-65. LAP LAMBERT Academic Publishing.

[2] Bii, K. J. (2019). Effect of collaborative concept mapping teaching strategy on students' attitudes towards mathematics in secondary schools in Kenya. International Journal of Education and Research, 7 (7) 57-74

[3] Busari, A. O. \& Akinoso S. O. (2020). Mathematics Anxiety and Personality Characteristics of Secondary Schools Students in Lagos State. Journal of Positive Psychology and Counselling 6, 12-23.

[4] Firestone, M. (2006). Collaborative skill: Definition and explanation. http://study.com/academy/lesson/collaborative-skillsdefinition-lesson-quiz.html

[5] Fonseka J.R. (2012). Students' attitude towards math learning. In Seel N.M. (eds.) Encyclopedia of the Sciences of Learning. Springer, Boston, MA. Available from https://doi.org/10.1007/978-/-4419-1428-6 1078

[6] Galton, M., Hargreaves, L., \& Pell, T. (2009). Group work and whole-class teaching with 11-14 years old compared. Cambridge Journal of Education. 39 (1), 119-140. www.eric.ed.gov

[7] Ifamuyiwa, S. A. \& M. K. Akinsola, (2008). Improving secondary school student's attitude towards mathematics through self and cooperative instructional strategies. International Journal of Mathematics Education Science Technology, 39: 569-585. DOI: 10.1080/00207390801986874

[8] Kennedy, L. (2019, September 30). How attitude towards math impacts student achievement [Blog post]. Retrieved from https://www.prodigygame.com/main.en/blog/attitude-towardsmath/ 
[9] Khaoo, S. T., Ainley, J. (2005). Attitudes, intentions, and participation: Longitudinal survey of Australian youth. Victoria: Australian Council for Educational Research.

[10] Olanrewaju, M. K. (2019). Effect of collaborative learning technique and mathematics anxiety on mathematics learning achievement among secondary school students in Gombe State, Nigeria. Legacy University, the Gambia, pp 1-12.

[11] Stoner, D. A. (2004). The effect of cooperative learning strategies on mathematics achievement among middle-grades students: A meta: analysis. The doctoral dissertation of the University of Georgia.

[12] Thayer-Bacon, B. J. (2000). Transforming critical thinking: Thinking constructively. New York: Teachers college press.

[13] Tapia, M., \& Marsh, G. E. II. (2004). An instrument to measure mathematics attitudes. Academic Exchange Quarterly, 8(2), 16-21.

[14] Tarim, K. \& Akdeniz, F. (2008), The effects of cooperative learning on Turkish elementary students' mathematics achievement and attitude towards mathematics using TAI and STAD methods. Educ. Stud. Math., 67: 77-91. 